\title{
C-C Chemokine Receptor Type 5 Measurement
}

National Cancer Institute

\section{Source}

National Cancer Institute. C-C Chemokine Receptor Type 5 Measurement. NCI

Thesaurus. Code C122103.

The determination of the amount of C-C chemokine receptor type 5 in a biological specimen. 